\title{
O ESTADO E A EXCEÇÃO
}

\section{OU O ESTADO DE EXCEÇÃO?!}

\author{
FRANCISCO DE OLIVEIRA
}

Os oprimidos sabem do que se trata Walter Benjamin. Teses sobre a História.
1 Este texto foi preparado como base para a conferência de abertura do X Encotro Nacional da ANPUR Associação Nacional de Pós-Graduação e Pesquisa em Planejamento Urbano e Regional, Belo Horizonte, 26.5.2003.

R E S U M O O texto discute o papel do Estado hoje no Brasil e em particular o do planejamento. Se historicamente as relações entre o Estado e o urbano pautaram-se por um esforço de normatividade da relação capital-trabalho, cabendo ao planejamento enquadrar a exceção e transformá-la em norma, transformaçōes radicais recentes na economia e sociedade brasileiras sugerem que a exceção parece ter enquadrado o planejamento. Às desigualdades históricas da sociedade brasileira vieram juntar-se aquelas advindas da reestruturação produtiva e da globalização, reformatando o mercado, funcionalizando a relação Estado-capital, transformando politicas sociais em antipoliticas de funcionalização da pobreza, erigindo em norma o que antes dela se afastava, pontuando um esforço teórico que transitou da busca da normatividade para a racionalização da exceção.

P A L A V R A S - C H A V E Relaçôes Estado-urbano; planejamento urbano; desigualdade social; Brasil.

\section{UMA BREVE HISTÓRIA DO TEMPO PERDIDO}

Num passado que pode ser localizado no século XX - o breve, segundo Hobsbawm - as relações entre o Estado e o urbano, o Estado e o planejamento podiam ser caracterizadas, ainda que toscamente, como o de um enorme esforço de normatividade para lograr estabelecer a relação capital-trabalho, promover as condições gerais da produção para a industrialização, utilizando, para tanto, até o limite, a coerção estatal como substituto do mercado, e finalmente, no capítulo da relação com o planejamento, inventar uma política que metamorfoseasse o conflito de classes numa "convergência de contrários", sem jogo de soma zero, anti-schmittiana no sentido de eliminar a relação amigo-inimigo. A cidade era o teatro dessas operaçôes e todas as formas de planejamento de alguma maneira buscavam funcionalizá-la - na maior parte das vezes almejando-se ingenuamente a supressão do conflito - para uma nova divisão social do trabalho e novas relações de classe. Numa palavra, ainda que com métodos excepcionais, tais relações tinham como norte paradigmático enquadrar a exceção e transformá-la em norma.

Seria longo, fastidioso e pretensioso resumir o intenso processo de transformaçóes que alterou radicalmente a economia e a sociedade brasileiras, fazendo a industrialização, urbanizando-a totalmente, tutelando o conflito de classe, utilizando a coerção estatal como força propulsora e ordenadora tanto do aprofundamento do capitalismo quanto de suas relações sociais de produção, o que quer dizer, em geral, planejando. Mas tais transformações e seus métodos não lograram normatizar o excepcional, enquadrando a exceção. Parafraseando uma frase de Paul Baran, dita há muito tempo, não foi o planejamento que enquadrou a exceção, mas foi a exceção que enquadrou o planejamento. 
No fundo desse processo, jaz a enorme desigualdade que marca a sociedade brasileira. Toda a transformação ocorrida fundou outra desigualdade, qualitativamente diferente sobretudo quando vista sob a ótica da liberdade, e quantitativamente maior se observadas as distâncias entre os muito ricos e os muito pobres. Mas a nova diferença quantitativa obriga os dominados a um esforço descomunal para superá-la, o que introduz uma nova qualidade na desigualdade, que, se já não é a completa ausência de liberdade, é a quase completa ausência de horizonte de superação. De fato, embora continuemos a ser uma sociedade racista, na semântica social e nas relações sociais o escravismo foi superado. Mas superar a desigualdade capitalista supõe poder superar o próprio capitalismo, o que é uma tarefa de titãs.

Seria fácil dizer que a herança escravista foi sempre o grande obstáculo para a igualdade, com o que se estará dizendo uma meia-verdade: o Sul dos Estados Unidos foi tão ou mais escravista que o Nordeste brasileiro - lá chegou-se até à fazenda de criação de escravos - o que sugere que Casa grande \& senzala é o nosso E o vento levou. Deixo de graça essa sugestão para o novo cinema brasileiro, já que as reconstituições da Globo não conseguem criar o clima de nostalgia de um temps perdu, que é a chave do apelo do romance e do charmoso filme. Mas o Sul norte-americano, sob a pressão hegemônica do Norte industrializado, finalmente venceu a barreira escravista, cujo epílogo foi a brava campanha de direitos civis da segunda metade do século XX. Nossa cordialidade, que resolveu a abolição sem sangue - de novo, os escravos sabiam o que queria dizer isso - não foi capaz de impor ao Norte - nos adverte Evaldo Cabral de Melo que Nordeste é uma invenção do século XX - escravista a ética do Sudeste industrializado.

A coerção estatal também foi característica de todos os capitalismos tardios, entre os quais se sobressaem a Alemanha e a Itália. Mas os dois países "excepcionais", justamente onde a besta nazi-fascista sentou suas patas sujas de sangue, transformaram-se em democracias exemplares e varreram com a desigualdade, de forma que hoje comparecem entre os mais igualitários, sob o forte impulso de crescimento do capitalismo nos Trinta Anos Gloriosos. Conhecemos as regressões que a Itália vem experimentando, mas nada comparável ao país semi-feudal que o neo-realismo retratou. A forma autoritária e muitas vezes ditatorial também não é argumento suficiente, embora necessário, para explicar o caso brasileiro.

Não foi ausência de crescimento capitalista o que explica a profunda desigualdade: pelo contrário, o intenso crescimento durante um século talvez esteja, paradoxalmente, entre suas causas mais importantes. Sob as tenazes do excepcional crescimento, combinado com a herança escravista e a poderosa coerção estatal, o estatuto da força de trabalho rebaixado para tutela estatal produziu a extorsão da plus-valia mais avantajada e uma distribuição da renda que se iguala à dos mais pobres países da África, onde "capitalismo" é somente força de expressão. Essa compactação de tempo histórico, no século XX, em que parece que toda a letargia do livre-cambismo do século precedente, que obstaculizou a industrialização, foi acelerada até o limite, chamou para regimes de exceção, na longa "via passiva". Se o nazismo durou apenas doze anos na Alemanha e o fascismo, no máximo vinte na Itália, nossas ditaduras na segunda metade do século XX alcançaram a invejável (?) marca de 35 anos, igualando-se a Franco e Salazar. A desigualdade brasileira mora aí.

A progressão da relação salarial foi coartada no começo dos anos oitenta do século passado pela combinação da reestruturação produtiva com a globalização; isto forneceu as bases para um enorme avanço da produtividade do trabalho que jogou para as calen- 
das a possibilidade e/ou necessidade da relação formal de trabalho: pelo contrário, o que se chamou no passado de "informalidade" tornou-se a regra. Pede-se ao trabalhador formal os atributos do "informal": flexibilidade, polivalência, iniciativa. Tais atributos encontram-se nos camelôs dos centrôes de nossas cidades. Aparece aí o primeiro elemento da exceção: o mercado de trabalho foi virado pelo avesso.

A revolução molecular-digital atuando sobre um mercado de trabalho mais flexível que as canas do deserto de que falava São João - o das festas juninas, não o evangelista - pavimenta a flexibilização, de modo a produzir o espantoso fenômeno de que os vendedores ambulantes de refrigerantes e cerveja nas portas dos estádios duas vezes por semana - lembram Milton Nascimento: "Brasil vazio nas tardes de domingo/isto é o país do futebol" - tornaram-se funcionais para o capital financeiro. O formidável ataque ideológico neoliberal formatou um consenso pelo avesso: tudo que era sólido desmancha-se no ar. Emprego estavel é privilégio, regras de previsibilidade foram traduzidas como burocracia.

A financeirização das economias e principalmente dos orçamentos públicos retira autonomia do Estado; produz-se uma autonomização do mercado, que é o outro pilar da exceção. Mas a contradição está em que tornado supérfluo pela autonomização, o Estado se funcionaliza como uma máquina de arrecadação para tornar o excedente disponível para o capital. E a exceção está em que as políticas sociais não têm mais o projeto de mudar a distribuição da renda - que foi lograda ao longo da experiência do Welfare, não tenhamos o falso pudor de não admiti-lo, como os partidos comunistas não quiseram reconhecer o papel do reformismo social-democrata - e se transformaram em antipolíticas de funcionalização da pobreza.

O que estou descrevendo é o Ornitorrinco, com maísculas, porque tornou-se o novo "modo de produção" da periferia capitalista. Capital financeiro na cabeça, informatização em todos os meios de produção e de consumo, dívida externa que representa um adiantamento de não menos que $40 \%$ sobre o PIB e porcentagem mais alta para a dívida interna, setor financeiro com $9 \%$ do PIB, proporção que nem os USA e o UK, principais centros financeiros do capitalismo globalizado alcançam, altíssima informalidade que beira os $60 \%$ da PEA, pobreza na qual vegetam 70 milhôes - $41 \%$ da população - abaixo da linha dos US\$2/per capita/dia (em 1998, segundo o PNUD) e que é concomitante e provocada pela digitalização-molecularização do capital. Isto é, mamífero com bico e patas de pato, semi-aquático, cujas mamas são pêlos, e... que se reproduz oviparamente, modo barroco de dizer: bota ovo.

As cidades são os lugares por excelência dessas exceções, e o conjunto delas é a administração da exceção. Trata-se de um Estado de Exceção, na medida justa da teoria schmittiana, pois o soberano é o que decide a exceção: quem é o soberano? O mercado, não como abstração, mas precisamente o que coloca $41 \%$ abaixo da linha da pobreza. Pensemos: o subdesenvolvimento não era a exceção, era uma singularidade histórica, que assinalava precisamente que ele havia sido produzido pelo capitalismo em expansão, o qual, montando-se sobre sociedades criadas ou apropriadas para produzir o excedente que na verdade criou o capitalismo mercantil, não poderia, jamais, reproduzir o original. Roberto Schwarz mostrou isso magnificamente em sua interpretação de Machado de Assis, a chamada originalidade da cópia, título que FHC apropriou para responder às críticas sobre a "teoria" da dependência.

O Ornitorrinco é a exceção permanente, porque já não é singularidade: ele contém todos os elementos do original desenvolvido, já não há espaços pré-capitalistas, já não há 
fronteiras de expansão do capital. O alto desemprego - 20\% em São Paulo - não é sinal de desocupação de fatores - obrigado, neoclássicos - por insuficiência de capital, mas, o contrário, por excesso de capitalização. É a cópia do original que causa o desemprego e a péssima distribuição de renda, que se agravará na medida em que o desenvolvimento é retomado, e o será, de forma intermitente, mas sem sustentabilidade.

Uma vez mais, convoco ao exame empírico: as políticas chamadas de emprego e renda são a exceção do desemprego; elas aprofundam o desemprego, ou o mantém, com o propósito de combatê-lo! As políticas de mutirôes para satisfazer a demanda por habitação são a cidade como exceção; é a desmercantilização da força de trabalho sob a forma de trabalho virtual que prepara o enorme exército "informal" - utilizo o termo apenas porque é do nosso jargão, para economizar, mas ele já não tem poder explicativo - para as portas dos estádios de futebol, ou os arredores dos formosos teatros, ou as bancárias e banqueiras ruas dos centros de nossas cidades. O Fome Zero é o marketing como política. Mesmo uma "política" contra a qual ninguém pode colocar-se, a cópia brasileira das políticas chamadas afirmativas, de que as cotas para os negros na universidade pública a UERJ no Rio é a pioneira - é uma política de exceção que revela a derrota do projeto de integração. A síntese é a dependência financeira externa do Estado, que come 9\% do PIB como serviço da dívida, equivalente a mais da metade do coeficiente de inversão. É a exceção do Estado ou o Estado como exceção.

A consequência das exceções parciais, que forçamos a barra para pensá-las ainda no paradigma da normatividade porque nos assusta pensar na exceção totalizadora, é que o "normal", a norma, é puxada para baixo pelo "anormal": esta é a síntese que faz a exceção. A enorme desigualdade obriga a pensar que se faz necessário baratear as escolas, para aumentar o número de incluídos: a consequência é planejarmos escolas pobres para pobres. A arrogância do caos do trânsito - já uma transgressão semântica porque se trata de um problema de transporte e não de trânsito - obriga-nos a planejar zonas azuis, a exceção para os que têm automóveis, rodízio de automóveis, zoneamento que preserve os bairros ricos da contaminação com os pobres, a "revitalização" dos centros - alguém perguntou a uma conhecida urbanista, olhando do alto de um dos prédios do Anhangabaú se lá em baixo não havia gente ou aquilo era um formigueiro - para nos livrar da deterioração causada não pela invasão dos pobres, mas pela especulação que criou sucessivamente a avenida Paulista, deslocou-se para a Faria Lima, transferiu-se para o eixo da Berrini, em falando da capital de São Paulo. Mas a "revitalização" faz-se necessária, teorizou outra urbanista, porque putas, rufiōes, bêbados e desempregados "privatizaram" o espaço público! Hanah Arendt se debateu ferozmente no túmulo quando ouviu tamanha "exceção"! As empresas se assenhoream das políticas sociais, e a exceção do mercado se impõe como critério das políticas, porque precisa-se de eficiência e produtividade nas políticas sociais, e o resultado é maior exclusão.

O planejamento urbano, com suas regras de utilização do solo, corredores de tráfego, corredores comerciais, camelódromos, barraquinhas coloridas para disfarçar a precariedade, quais outras Catarina da Rússia, legalização de perueiros e ônibus clandestinos forçada pela chantagem, é a cidade como exceção: ele busca se compatibilizar com as piores tendências de concentração da renda e da sociabilidade indesejável quase obrigatória das classes que voltaram a ser chamadas de "perigosas", como são conhecidas as que foram uma vez "laboriosas". No Rio, cuja geografia não consegue separar ricos e pobres, há um clamor pela policialização total da cidade, e na mistura de tiros que já não se sabe de 
onde provêm, as balas perdidas deixaram de ser exceção à regra: ao contrário, a exceção é quem nunca correu esse risco.

O summa cum laudae é a criminalidade, em todas as suas formas. A mais ostensiva é hoje a do narcotráfico: que é a exceção do mercado de trabalho, pois, como na Colômbia, Bolívia e Peru, não há como as atividades "normais" competirem com os rendimentos proporcionados pela produção e comercialização dos entorpecentes, nem pelo emprego - pode-se chamar isso de emprego? - dos pequenos "aviōes" pelo narcotráfico. A foto mais dramática dos episódios do Rio que se intensificaram às vésperas do carnaval era provavelmente no $O$ Globo - de um imenso cordão de esfarrapados, cujo fashion era composto de uma miserável bermuda e um par de chinelos de dedo, cópia da famosa Havaiana, descendo o morro, aprisionados. O humorista que é hoje o melhor sociólogo-antropólogo do Brasil, Zé Simão, satirizou com soda cáustica: "O elemento procurado é pardo, traja bermuda e sandália tipo Havaiana. Tão procurando o Brasil!” (Folha de S.Paulo, data indeterminada). O retrato sem retoques de uma sociedade derrotada. $\mathrm{O}$ alto lucro é diretamente proporcional ao alto risco, isso já se sabia, e neste caso a ligação interna-externa se dá porque o grande consumidor está nos paises desenvolvidos: é a nossa nova "dependência".

Mas o lado menos ostensivo da criminalidade, que não aparece sob este rótulo, está nas taxas de homicídios, a segunda causa-mortis na cidade de São Paulo, que devasta a faixa etária masculina entre os 15 e os 24 anos. Todos sabemos que a maior parte dos crimes se dá entre conhecidos e até entre membros do grupo familiar. Como mostram algumas excelentes pesquisas antropológicas e sociológicas, é a promiscuidade por ausência de relação mercantil que detona os conflitos, e leva aos homicídios. Essa ausência tem um nome: desemprego.

$\mathrm{Na}$ tentativa de conter a avalanche, a policialização da sociedade, a segurança elevada ao valor maior, o pedido de transformar as Forças Armadas em polícia urbana, uma guerra civil mal disfarçada. A morte da pólis é a morte da política e a negação da negação: todo espaço público deve ser privatizado, deve estar sob o olhar panóptico, porque o perigo é o público. Até no futebol a exceção já se instalou, porque no carnaval ele já é a regra: a recente Lei do Torcedor manda instalar câmaras em todos os estádios, para conter o vandalismo e flagrar os violentos. Não há mais política: há tecnicidades e dispositivos foucaultianos que se impõem com a lei da necessidade. Adequamos nosso discurso para reconhecer a "realidade" e em nome dela, planejar a exceção. Reconheçamos: nosso esforço teórico transitou da busca da normatividade para a racionalização da exceção, que nossa prática cotidiana já leva a cabo faz tempo. Porque do nosso horizonte já sumiram as transformações. Sejamos pragmáticos, já é tempo e já estamos na idade, ora bolas, de abandonar as utopias!

A B S T R A C T The text looks at the role played by the State in Brazil today and in particular the role of planning. If, historically, the relationships between the State and the urban were based on an effort to ease the relationship between capital and labor, planning to control the exception and to transform it into the rule, recent radical changes in the Brazilian economy and society suggest that the exception has itself curbed planning. To the inequalities typical of Brazilian society were added those stemming from the productive re-structure promoted by globalization, which re-shaped the market, re-purposing the relationship between State and capital, while turning social policies into anti-policies of poverty, transforming into
Francisco de Oliveira é professor titular aposentado do Depto. de Sociologia da FFLCH/USP e coordenadorcientífico do Centro de Estudos dos Direitos da Cidadania - CENEDIC/USP.

Artigo recebido para publicação em junho de 2003. 
the rule what beforehand was considered a deviation from it and promoting a theoretical effort the aim of which is to rationalize the exception and turn it into the norm.

K E Y W O R D S Relationship State-urban; urban planning; social; inequality; Brazil. 